\title{
Influence of $\gamma$-Phase on the High- Temperature Oxidation of NiAl-Fe Alloys
}

\author{
Maurício de Jesus Monteiro $^{\mathrm{a}}{\text { Fernando Rizzo Assunção }{ }^{\mathrm{a}} \text {, Zeng Chaoliu }}^{\mathrm{b}}$ \\ ${ }^{a}$ Departamento de Ciências dos Materiais e Metalurgia, Pontifícia Universidade \\ Católica do Rio de Janeiro, C.P. 38008, 22453-900 Rio de Janeiro - RJ, Brazil; \\ ${ }^{\mathrm{b}}$ Chinese Academy of Sciences, State Key Laboratory for Corrosion and Protection, \\ Institute of Corrosion and Protection of Metals, 110015 Shenyang, China
}

Received: August 15, 1998; Revised: March 30, 1999

\begin{abstract}
The oxidation of NiAl, NiAl-20at.\%Fe and NiAl-30at.\%Fe at $1000-1100{ }^{\circ} \mathrm{C}$ in air has been studied. Pure NiAl shows excellent oxidation resistance due to the formation of an $\mathrm{Al}_{2} \mathrm{O}_{3}$ layer. $\mathrm{NiAl}-20 \mathrm{Fe}$ also shows good oxidation resistance due to the formation of an $\mathrm{Al}_{2} \mathrm{O}_{3}$ scale on a $\beta$-phase substrate. Moreover, some nodules consisting of mixed oxides of $\mathrm{Fe}$ and $\mathrm{Ni}$ grow over the ductile $\gamma$-phase surface incorporated to the $\beta$-phase substrate. NiAl-30Fe alloy undergoes a much faster oxidation due to the formation of a non-protective $\mathrm{Fe}$ and Ni-rich scale, which is extremely susceptible to spallation. The addition of $\mathrm{Fe}$ to $\mathrm{NiAl}$ is detrimental to its oxidation resistance.
\end{abstract}

Keywords: intermetallic compounds, $\mathrm{NiAl}, \mathrm{Fe}$, oxidation

\section{Introduction}

$\mathrm{NiAl}$ is an intermetallic compound with $\beta$ structure, which is considered as a candidate for high temperature structural material due to its high melting point, low density, good heat conductivity and excellent oxidation resistance $^{1,2}$. Nevertheless, it has low room-temperature ductility and poor high temperature creep resistance. It has been shown that the addition of $\mathrm{Fe}$ to NiAl can improve its high-temperature creep resistance ${ }^{3}$ and room temperature ductility $^{4}$. This improvement in ductility is usually acchieved by introducing some ductile $\gamma$ phase in the alloy. Increasing the content of $\mathrm{Fe}$ in the alloy will increase the content of $\gamma$ phase and as a result the alloy shows improved room-temperature ductility. Because the $\beta$-phase is rich in $\mathrm{Al}$, but the $\gamma$ phase is poor in $\mathrm{Al}, \mathrm{Fe}$-containing NiAl alloys show a special corrosion behavior, although the alloy has high $\mathrm{Al}$ content. Before considering Ni-Al-Fe alloys for practical aplications, it is necessary to understand their corrosion behavior in the possible service environments. The present study examines the high temperature oxidation in air of two Fe-containing NiAl alloys i.e. NiAl-20at.\%Fe and NiAl-30at\%Fe.

\section{Experimental}

The materials selected for the present study are pure $\mathrm{NiAl}, \mathrm{NiAl}-20 \mathrm{at} . \% \mathrm{Fe}$ and NiAl-30at.\%Fe alloys. The chemical composition of $\mathrm{NiAl}$ (atomic percent) is stoichiometric Ni-50Al. NiAl-20Fe (referred to as alloy 20 in the text) is $\mathrm{Ni}-27 \mathrm{Al}-20 \mathrm{Fe}-0.003 \mathrm{Y}-0.003 \mathrm{Ce}$. NiAl-30Fe (referred to as alloy 30 in the text) is $\mathrm{Ni}-20 \mathrm{Al}-30 \mathrm{Fe}-0.003 \mathrm{Y}$. Rods of the cast alloys contained in a carbon steel pipe were hot-pressed after being preheated to $700{ }^{\circ} \mathrm{C}$ and then kept at $1100{ }^{\circ} \mathrm{C}$ for $1 \mathrm{~h}$. After hot pressing, the $\mathrm{NiAl}$ alloy was heat-treated at $900{ }^{\circ} \mathrm{C}$ for $1 \mathrm{~h}$ followed by furnace cooling; the alloy 20 was heat treated at $950{ }^{\circ} \mathrm{C}$ for $1 \mathrm{~h}$ and the alloy 30 at $1050{ }^{\circ} \mathrm{C}$, also for $1 \mathrm{~h}$, and both were air cooling. The oxidation treatment was carried out during $490 \mathrm{~h}$ in a high-temperature furnace at 1000 and $1100{ }^{\circ} \mathrm{C}$ under air atmosphere. The corroded specimens were analyzed by XRD and SEM coupled with EDAX.

\section{Experimental Results}

\subsection{Alloy composition}

Alloy 20 is mainly composed of the $\beta$ phase (gray) with little $\gamma$ phase (bright), as shown in Fig. 1a. The composition of the $\beta$ phase is $31.64 \% \mathrm{Al}, 20.71 \% \mathrm{Fe}$, Ni bal. (in atomic percent), and $\gamma$ is $14.11 \% \mathrm{Al}, 41.02 \% \mathrm{Fe}$, Ni bal. Alloy 30 is composed of the $\beta$ phase (gray) and the $\gamma$ phase (bright), as

e-mail: mauricio@dcmm.puc-rio.br 
shown in Fig. 1b. The composition of the $\beta$ phase is $32.56 \% \mathrm{Al}, 21,55 \% \mathrm{Fe}, \mathrm{Ni}$ bal., and that of the $\gamma$ phase is $\mathrm{Al}$ 14.16, Fe 43.46, Ni bal.

\subsection{Scale composition}

Scale spallation was not observed during the oxidation of NiAl. Little spallation of the scale grown on alloy 20 was observed. Conversely, alloy 30 underwent servere scale spallation during oxidation, but especially during cooling of the oxidized samples. XRD was used to examine both the spalled oxides and those left on the alloy surface. The surface analysis results showed the presence of a pure $\alpha-\mathrm{Al}_{2} \mathrm{O}_{3}$ scale on the NiAl surface. Alloy 20 also formed $\alpha-\mathrm{Al}_{2} \mathrm{O}_{3}$ with little $\mathrm{Fe}_{2} \mathrm{O}_{3}, \mathrm{Fe}_{3} \mathrm{O}_{4}$ and $\mathrm{NiFe}_{2} \mathrm{O}_{4}$. Instead of an $\mathrm{Al}_{2} \mathrm{O}_{3}$ scale, a mixed scale containing $\mathrm{Fe}_{2} \mathrm{O}_{3}, \mathrm{Fe}_{3} \mathrm{O}_{4}$, $\mathrm{NiFe}_{2} \mathrm{O}_{4}$ and $\mathrm{FeAl}_{2} \mathrm{O}_{4}$ oxides were formed on the alloy 30 surface. For alloy 30 the spalled oxides had similar composition to those left on the alloy surface.

Figure 2 shows the cross-sectional morphology of $\mathrm{NiAl}$ alloy oxidized at $1100{ }^{\circ} \mathrm{C}$ : a thin $\mathrm{Al}_{2} \mathrm{O}_{3}$ layer forms on the alloy surface. Some cracks exist across the scale and voids are present along the scale/alloy substrate interface.

Alloy 30 , oxidized at both $1000^{\circ} \mathrm{C}$ and $1100^{\circ} \mathrm{C}$, shows similar cross-sectional morphologies. Figure $3 \mathrm{a}$. and $\mathrm{b}$ show the cross-sections of alloy 30 oxidized at $1100{ }^{\circ} \mathrm{C}$ for $490 \mathrm{~h}$. The outer layer is mainly composed of Fe an Ni-rich oxides, containing $\mathrm{Fe}$ oxides (gray) and $\mathrm{NiFe}_{2} \mathrm{O}_{4}$ (bright) (Fig. 3a.). Al-containing oxides such as $\mathrm{FeAl}_{2} \mathrm{O}_{4}$ are present in the inner layer. Moreover, an $\mathrm{Al}_{2} \mathrm{O}_{3}$-rich scale (black) forms along the discontinuos scale/substrate alloy interface. In addition, oxidation develops into the alloy, forming mainly $\mathrm{FeAl}_{2} \mathrm{O}_{4}$ and $\mathrm{Al}_{2} \mathrm{O}_{3}$ (Fig. 3b).

The cross-sections of alloy 20 corroded at $1100^{\circ} \mathrm{C}$ (Fig. 4) shows the formation of an $\mathrm{Al}_{2} \mathrm{O}_{3}$ scale on the alloy surface (Fig. 4a.), and of an Al-depleted layer in the alloy substrate. Meanwhile, nodules rich in $\mathrm{Fe}$ and $\mathrm{Ni}$ oxides also

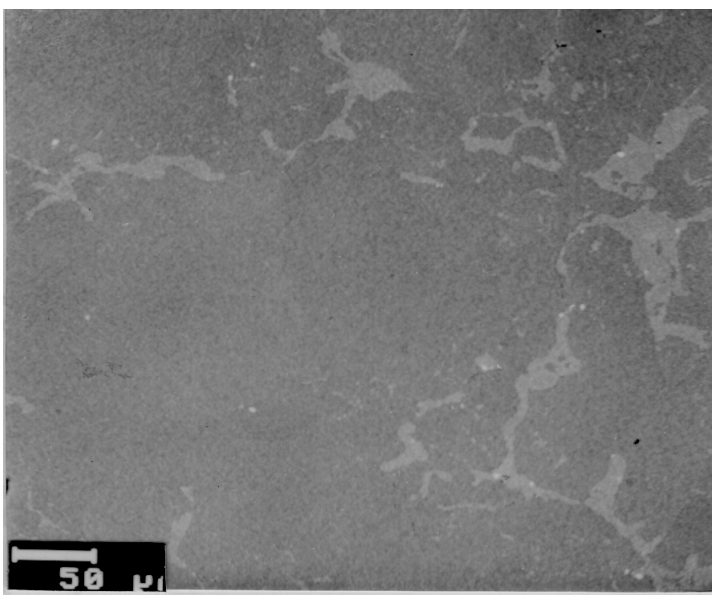

formed on the alloy surface, which mainly developed over the $\gamma$ phase incorporated to the $\beta$-phase substrate(Fig. 4b). Moreover, oxidation along the $\gamma$ phase developed deep into the alloy substrate, forming Al-rich oxides. The Al-depleted layer developed under $\mathrm{Al}_{2} \mathrm{O}_{3}$ scale may join with the $\gamma$ phase.

\section{Discussion}

Pure NiAl alloy has an excellent oxidation resistance due to the formation of a protective $\mathrm{Al}_{2} \mathrm{O}_{3}$ layer, just as observed in the present study. The oxidation of pure NiAl has been widely discussed in many studies ${ }^{5-7}$.

The addition of Fe to NiAl obviously has a detrimental effect on its oxidation resistance. The addition of Fe changes single $\beta$-phase structure of $\mathrm{NiAl}$ into a two-phase structure $(\beta+\gamma)$. A change in the Fe content of the alloy will directly affect the difference between the amount of the $\beta$ and $\gamma$ phases in the alloy. The change of the alloy

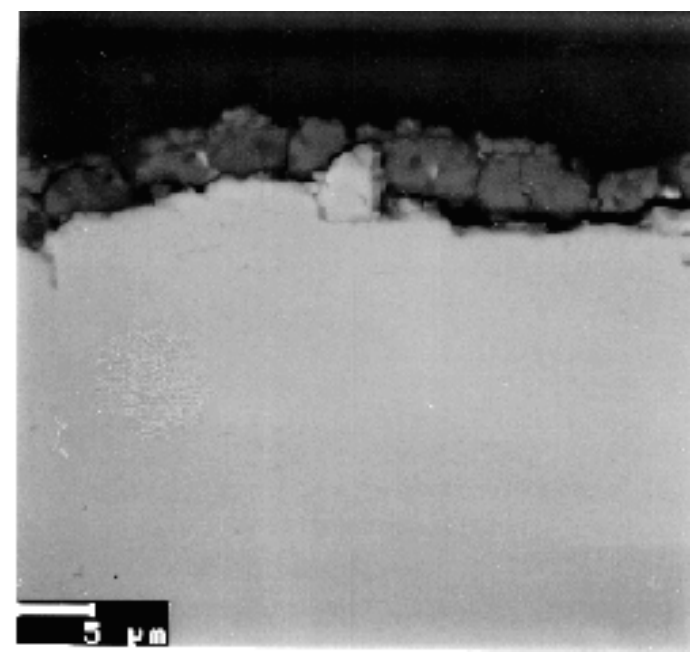

Figure 2. Cross-sectional morphology of $\mathrm{NiAl}$ after oxidation at $1100{ }^{\circ} \mathrm{C}$ for $490 \mathrm{~h}$.

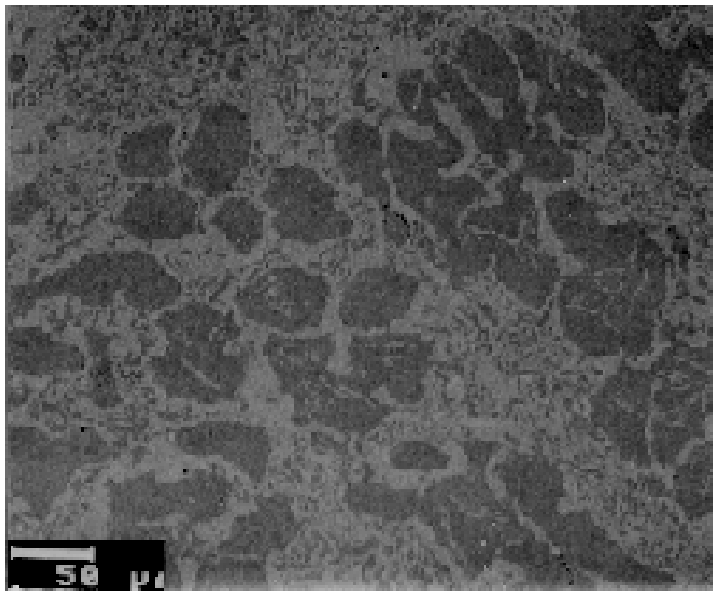

Figure 1. Microstructure (BEI) of NiAl-20Fe (a) and NiAl-30Fe (b) alloys. Dark phase: $\beta$; light phase: $\gamma$. 

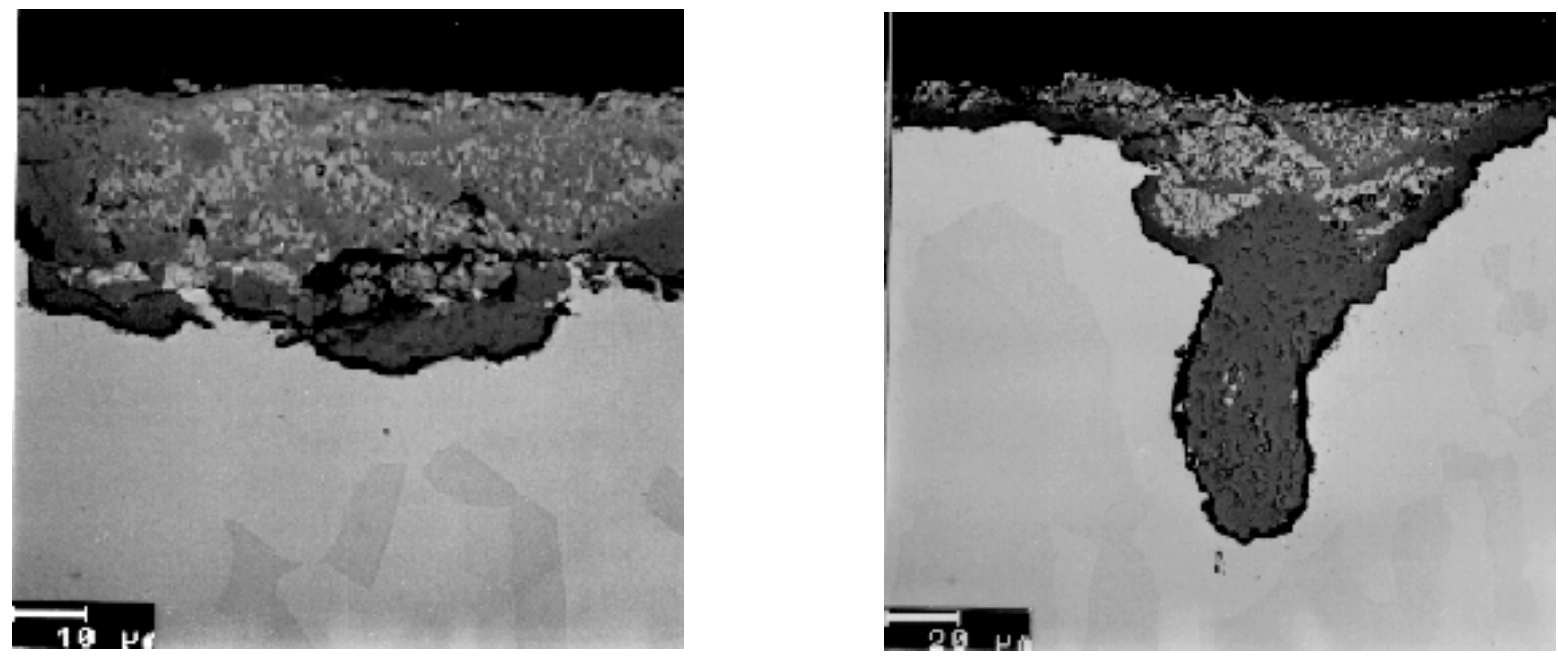

Figure 3. Cross-sectional morphologies of NiAl-30Fe alloy after oxidation at $1100{ }^{\circ} \mathrm{C}$ for $490 \mathrm{~h}$.
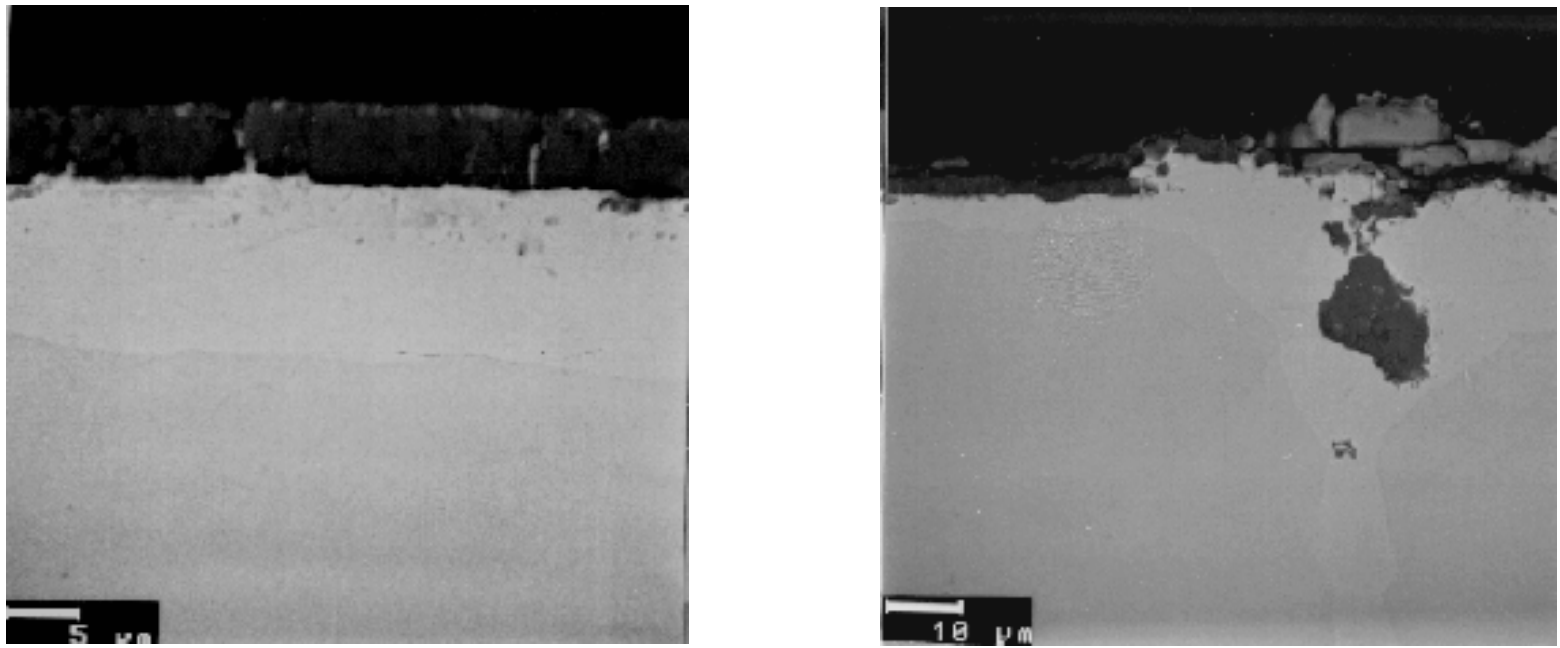

Figure 4. Cross-sectional morphologies of NiAl-20Fe alloy after oxidation at $1100{ }^{\circ} \mathrm{C}$ for $490 \mathrm{~h}$ (a) and $100 \mathrm{~h}(\mathrm{~b})$

microstructure also affects its oxidation mechanism, since the two phases will be exposed to the oxidizing atmosphere simultaneously. In fact, an $\mathrm{Al}_{2} \mathrm{O}_{3}$ scale can grow more easily on the $\beta$ phase surface because the $\beta$ phase has a higher $\mathrm{Al}$ content. Conversely, a scale rich in $\mathrm{Fe}$ and $\mathrm{Ni}$ oxides tends to form on the $\gamma$ phase surface due to its lower $\mathrm{Al}$ content.

For alloy 20 , the $\beta$ phase is the main constituent alloy, so that an $\mathrm{Al}_{2} \mathrm{O}_{3}$ scale can form rapidly on its surface, producing an $\mathrm{Al}$ depletion in the base alloy. Because of the slow growth rate of $\mathrm{Al}_{2} \mathrm{O}_{3}$ and of the rapid growth rate of $\mathrm{Fe}$ and $\mathrm{Ni}$ oxides, a mixed scale rich in $\mathrm{Fe}$ and $\mathrm{Ni}$ may grow over the $\gamma$ phase, forming oxides nodules at places where the $\gamma$ phase is exposed to air. Furthermore, this kind of oxidation can develop deep into the alloy substrate, forming internal oxides. The spallation of the scale during the experiment is mainly associated with these nodules. The formation of an Al-depleted layer under the $\mathrm{Al}_{2} \mathrm{O}_{3}$ scale is detrimental to the alloy oxidation resistance because the alloy substrate may not be able to provide enough $\mathrm{Al}$ for the formation of a new $\mathrm{Al}_{2} \mathrm{O}_{3}$ scale if the initial $\mathrm{Al}_{2} \mathrm{O}_{3}$ scale spalls off. Thus, it is very important to improve the adhesion of the $\mathrm{Al}_{2} \mathrm{O}_{3}$ scale. The fact that the $\mathrm{Al}_{2} \mathrm{O}_{3}$ scale grown on the $\beta$ phase does not undergo spallation during the experiment may be related due to the presence of the rare earth elements in the alloy.

For alloy 30 , the $\gamma$ phase is the main constituent of the alloy. During oxidation, a mixed scale rich in $\mathrm{Fe}$ and $\mathrm{Ni}$ oxides can grow rapidly on this phase. Theoretically, an $\mathrm{Al}_{2} \mathrm{O}_{3}$ scale should form on the $\beta$ phase surface. Accordingly, the surface scale should be composed of a mixture of $\mathrm{Fe}$ and $\mathrm{Ni}$-rich oxides and $\mathrm{Al}_{2} \mathrm{O}_{3}$. However, only a 
surface scale rich in $\mathrm{Fe}$ and $\mathrm{Ni}$ oxides is observed, which may be atributed to the rapid growth of the $\mathrm{Fe}$ and $\mathrm{Ni}$ oxides and to the slow growth of the $\mathrm{Al}_{2} \mathrm{O}_{3}$ scale. The formation of a mixed scale may cause the enrichment of $\mathrm{Al}$ of the alloy surface, and as a result an $\mathrm{Al}_{2} \mathrm{O}_{3}$ rich scale may form in the inner layer. Because the mixed scale is extremely susceptible to spallation, the whole oxide spalls off frequently during the experiment, especially under heating and cooling cycles. After spallattion, the alloy surface is again exposed to air starting a new oxidation process. This process is repeated promoting a very fast alloy oxidaton.

The ductility improvement of NiAl is usually acchieved by the presence of the ductil $\gamma$ phase, which also transforms the single structure of NiAl into a two-phase structure. However, the above results show that these two-phase alloys, especially for high Fe contents, usually do not show a good oxidation resistance. For common superalloys such as the $\mathrm{Ni}$ and $\mathrm{Fe}$-based alloys, the formation of a protective $\mathrm{Al}_{2} \mathrm{O}_{3}$ scale usualy does not require very high $\mathrm{Al}$ contents. Compared to those superalloys, alloys 20 and 30 have higher Al contents, but they hardly form a continuous $\mathrm{Al}_{2} \mathrm{O}_{3}$ layer especially for the 30 alloy. This may be due to the two-phase structure of the alloys, but also to the presence of intermetallic phases which may decrease the $\mathrm{Al}$ activity in the alloy, due to a strong chemical bond, as observed in other systems containing intermetallic compounds ${ }^{8}$.

\section{Conclusions}

$\mathrm{NiAl}$ shows excellent oxidation resistance due to the formation of a protective $\mathrm{Al}_{2} \mathrm{O}_{3}$ oxide layer. The addition of $\mathrm{Fe}$ to $\mathrm{NiAl}$ affects the microstructure and the oxidation behavior of the alloys. The NiAl-20Fe alloy, which is almost a single phase alloy, shows good oxidation resistance. On the other hand, the oxidation of the NiAl-30Fe alloy is much faster than for NiAl. The two-phase structure of the Fe containing NiAl alloys is detrimental to their corrosion resistence. A proctetive coating is needed for their high temperature aplications.

\section{References}

1. Vedula, V.; Pathave, I. Aslanidis; Titran, R.H. Mat. Res. Soc. Symp. Proc., n. 39, p. 411, 1985.

2. Vedula, V.; J.R. Stephens Mat. Res. Soc. Symp. Proc., n. 81, p. 381, 1987.

3. Rudy, M.; Santhoff, G. Mat. Res. Soc. Symp. Proc., n. 39, p. 327, 1985.

4. Guha, S.; Munroe, R.P.; Baker, I. Mat. Res. Soc. Symp. Proc., n. 133, p. 633, 1989.

5. Rybicki, G.C.; Smialek, J.L. Oxid. Met., n. 32, p. 275 , 1989.

6. Grabke, H.J.; Steinhorst, M.; Brumm, M.; Wiemer, D. Oxid. Met., n. 35, p. 199, 1991.

7. Doychak, J.; Smialek, J.L.; Barret, C.A. TMS, Proc. Oxidation of High Temperature Internametallics, Grobstein, T.; Doychak, J., eds, v. 41, 1989.

8. Becker, S.; Rahmel, A.; Schorr, M.; Schutze, M. Oxid. Met., n. 38, p. 425, 1992. 